\title{
CONTROLE DE CONSTITUCIONALIDADE DE ATOS ADMINISTRATIVOS PELOS CONSELHOS JUDICIAIS
}

\section{Deny Eduardo Pereira Alves}

ISSUE DOI: $10.21207 / 1983.4225 .246$

\section{RESUMO}

Analisa o presente trabalho a possibilidade de controle de constitucionalidade de atos administrativos pelos conselhos judiciais brasileiros, quais sejam o Conselho Nacional de Justiça e o Conselho Nacional do Ministério Público verificando à luz da Constituição Federal de 1988 sua (i)legitimidade para anular atos administrativos considerados contrários ao texto, objetivos ou princípios constitucionais. Estuda-se o início dos conselhos judiciais com sua proposta de criação e os argumentos favoráveis à atuação administrativa no exercício da autotutela, guarda e zelo da Constituição.

Palavras-chave: Conselhos Judiciais. CNJ. CNMP. Constitucionalidade. Atos Administrativos.

\section{INTRODUÇÃO}

A Emenda Constitucional no 45/2004 conhecida como Reforma do Judiciário trouxe inovações jurídicas no texto constitucional tanto no âmbito das garantias e direitos fundamentais com a proclamação do direito 
da razoável duração do processo, como também inovações de caráter administrativo com a criação dos Conselhos Nacionais de Justiça e do Ministério Público, cada qual com atribuições estritamente administrativas, decorrentes do poder hierárquico.

Com instalações e funcionamento recentes, os Conselhos Nacionais têm tido atuação autônoma, firme e de certa forma odiosa por alguns setores interessados nos julgamentos administrativos proferidos. Não muito incomum, os Conselhos têm julgado e corrigido falhas em listas de promoção e remoção de servidores, magistrados e membros do Ministério Público, editado resoluções de caráter geral com vistas à orientação e homogeneização dos atos administrativos judiciários bem como conferido concretude ao texto e princípios constitucionais que, hipocritamente em alguns casos, são esquecidos veementemente.

$\mathrm{Na}$ esteira de conferência de concretude aos dispositivos constitucionais, não raro sobrepujam alegações de usurpação de competência pelos Conselhos de matéria reservada à apreciação do Supremo Tribunal Federal (STF) na sua função de guardião da Constituição desdobrada no controle de constitucionalidade, difuso ou concentrado.

A Emenda Constitucional $n^{\circ} 45 / 2004$ foi fruto das recomendações efetuadas no Documento Técnico n 319 do Banco Mundial sob o título de "O SETOR JUDICIÁRIO NA AMÉRICA LATINA E NO CARIBE: elementos para reforma" que consignou a necessidade da criação de conselhos judiciais com preponderância sobre a garantia de eficácia do sistema disciplinar, mas também com atuação em recursos humanos e administração em geral.

Ipsis litteris as recomendações mais importantes para nosso trabalho encontram-se delimitadas a seguir:

Existem diversas estruturas de sistema disciplinar. O conselho judicial, por exemplo, pode ter jurisdição sobre matérias disciplinares, somando-se ao sistema de nomeações e avaliações, criando, assim um sistema uniforme e um órgão central. Além disso, a análise e revisão dos casos deve ser conduzido por pessoas que não tenham tido um relacionamento anterior com os juízes em questão. Os conselhos judiciais podem receber alegações de conduta inadequada e realizar investigações iniciais. 
Não é necessário que o Conselho Judicial conduza as investigações, mas deve haver algum tipo de comissão que investigue as alegações de mau procedimento. (...)

Como parte de um sistema de nomeação e avaliação, diversos países da América Latina estabeleceram conselhos judiciais, geralmente detentores das seguintes competências: administração de cortes, recursos humanos e mau procedimento individual e das Cortes. Também podendo ter jurisdição tanto sobre as Cortes Inferiores, quanto sobre a Corte Suprema. Na Província de Tucuman, na Argentina, a criação do Conselho para o processo de nomeação tem assegurado a indicação de advogados mais qualificados, em todas as instâncias jurídicas. É importante ainda que os membros do conselho sejam independentes e não estejam concorrendo a nenhum cargo político nos partidos. A Argentina, Equador e Peru criaram recentemente esses organismos. Os Conselhos devem incluir a participação de membros do Judiciário, conselhos profissionais de advogados, cidadãos e o Executivo, quando estabelecido de forma similar ao proposto no Chile, devendo ser presidido por um magistrado, como no modelo boliviano. Na formação do conselho torna-se relevante considerar se os membros terão dedicação parcial ou integral. ${ }^{1}$

Verifica-se, portanto, que a criação dos Conselhos Nacionais foi precedida de amplo estudo técnico e comparado acerca da necessidade da instituição de um sistema central e controle que possibilite independência e afastamento da base com vistas ao melhor julgamento da situação que ora se coloca.

${ }^{1}$ BANCO MUNDIAL. O setor judiciário na América Latina e no caribe: elementos para reforma. Documento Técnico $\mathrm{n}^{\circ}$ 319. Disponível em < http://www.anamatra.org.br/uploads/document/00003439.pdf >. Acesso em dez 2013. 


\section{FUNÇÃO CONSTITUCIONAL DOS CONSELHOS NACIONAIS}

O Conselho Nacional de Justiça (CNJ) instalado em 14 de junho de 2005, segundo o Artigo 103-B, $\$ 4^{\circ}$ da Constituição da República, tem a função de promover o controle da atuação administrativa e financeira do Poder Judiciário, zelando pela observância dos princípios administrativos e apreciar, de ofício ou mediante provocação, a legalidade dos atos administrativos, podendo desconstituí-los, revê-los ou fixar prazo para que se adotem as providências necessárias ao exato cumprimento da lei. Função que igualmente é estabelecida para o Conselho Nacional do Ministério Público em relação aos seus membros.

Sobre esta atribuição, Bagatini a subdivide em políticas, administrativas (stricto sensu), de ouvidoria, correcionais, disciplinares, sancionatórias, informativas e propositivas ${ }^{2}$ ressaltando que todas elas são de cunho administrativo.

Na seara política, a atuação do CNJ e do CNMP trata de preservar a independência do Judiciário, que se justifica com a própria origem histórica dos Conselhos judiciais ao modelo nórdico-europeu ${ }^{3}$. A política regulamentar diz respeito à edição de atos normativos secundários, sem inovação na ordem jurídica, mas com a prerrogativa decorrente do poder hierárquico de estabelecer norma geral que obrigue a modificação de condutas e atos administrativos inferiores. Neste sentido, as recomendações a que alude o texto constitucional como possíveis de serem determinadas pelos Conselhos têm caráter mandamental.

Por ter decisões de caráter administrativo, segundo comando do Art. 5', XXXV c.c. Art. 102, I, alínea "r", as decisões emanadas dos Conselhos Nacionais são suscetíveis de serem reapreciadas pelo Poder Judiciário através do Supremo Tribunal Federal. Existe vedação, entretanto, para que os Conselhos Nacionais prolatem decisões administrativas a respeito de matérias previamente judicializadas ou que o venham a ser em momento

\footnotetext{
${ }^{2}$ BAGATINI, Júlia. Conselho Nacional de Justiça: um controle administrativo do poder judiciário?. In: Âmbito Jurídico, Rio Grande, XIV, n. 88, maio 2011. Disponível em: < http://www.ambito-juridico.com.br/site/index.php?n_link=revista_artigos_ leitura\&artigo_id=9498 >. Acesso em dez 2013.

${ }^{3}$ SAMPAIO, José Adércio Leite. Apud BAGATINI, Júlia. Ibidem.
} 
posterior em consagração ao princípio da segurança jurídica haja vista a concreta possibilidade de decisões conflitantes ${ }^{4}$.

No mesmo sentido é decisão do Supremo Tribunal Federal da lavra do Min. Ricardo Lewandowski nos autos do AgR-MS n ${ }^{\circ}$ 28.174/DF que diz:

AGRAVO REGIMENTAL. MANDADO DE SEGURANÇA. CONSELHO NACIONAL DE JUSTIÇA. NÃO CONHECIMENTO DE PROCEDIMENTO DE CONTROLE ADMINISTRATIVO. PRÉVIA JUDICIALIZAÇÃO DA MATÉRIA. MANDADO DE SEGURANÇA A QUE SE NEGOU PROVIMENTO. AGRAVO IMPROVIDO.

I - Não cometeu qualquer ilegalidade o $\mathrm{CNJ}$ ao de apreciar a questão que lhe foi submetida, uma vez que a matéria já estava sob o crivo da jurisdição.

II - o CNJ seja órgão do Poder Judiciário, possui tão somente atribuições de natureza administrativa e, nesse sentido, não lhe é permitido decidir de forma contrária ao estabelecido em processo jurisdicional. III - Agravo improvido. (MS 28174 AgR, Relator(a): Min. RICARDO LEWANDOWSKI, Tribunal Pleno, julgado em 14/10/2010, DJe-221 DIVULG 17-112010 PUBLIC 18-11-2010 EMENT VOL-02433-01 PP-00001)

Não está vedada, entretanto, a apreciação administrativa do pedido nos casos em que o pedido do processo judicial não comporte o pedido administrativo, ou no caso em que, embora sob o crivo da jurisdição o processo judicial seja julgado sem resolução de mérito nos termos do Artigo 267 do Código de Processo Civil anteriormente à apreciação administrativa posto que, entende-se, que não foi capaz de produzir efeitos limitadores à atuação dos Conselhos Nacionais.

\footnotetext{
${ }^{4}$ CNJ, PP n ${ }^{\circ}$ 0005458-71.2013.2.00.0000, Rel. Cons. Ana Maria Amarante, j. 180 ${ }^{\mathrm{a}}$ Sessão Ordinária; Recurso Administrativo no PP nº 0003813-11.2013.2.00.0000, Rel. Cons. Flavio Sirangelo, j. $176^{\mathrm{a}}$ Sessão Ordinária, dentre outros precedentes. CNMP, PCA n 0.00.000.000165/2011-42, Rel. Cons. Bruno Dantas, PCA n 0.00.000.001058/2012-12, Rel. Cons. Jarbas Soares e demais precedentes.
} 
Nos casos em que a matéria for julgada improcedente, ou seja, havendo conhecimento da matéria nos termos do Artigo 269, I "parte final" do Código de Processo Civil, a atuação do Conselho Nacional será de forma supletiva adstrita aos termos teleológicos da decisão judicial final. Tal atuação supletiva não pode se dar contrariu sensu da decisão judicial sob pena de sua violação exorbitar a competência administrativa conferida aos Conselhos Nacionais.

\section{CONTROLE DOS ATOS ADMINISTRATIVOS PELOS CONSELHOS NACIONAIS}

Previsto em ambos os Regimentos Internos do CNJ e do CNMP existe classe procedimental, denominada procedimento de controle administrativo (PCA), na qual há a apreciação da legalidade lato sensu, de ofício ou a requerimento, de ato administrativo também em amplo sentido em observância aos princípios administrativos constitucionais.

Assim, dispõem os Regimentos Internos do CNJ e do CNMP, nos artigos 91 e 123, respectivamente:

Art. 91. O controle dos atos administrativos praticados por membros ou órgãos do Poder Judiciário será exercido pelo Plenário do CNJ, de ofício ou mediante provocação, sempre que restarem contrariados os princípios estabelecidos no art. $37 \mathrm{da}$ Constituição, especialmente os de legalidade, impessoalidade, moralidade, publicidade e eficiência, sem prejuízo da competência do Tribunal de Contas da União e dos Tribunais de Contas dos Estados. (Regimento Interno do CNJ)

Parágrafo único. Não será admitido o controle de atos administrativos praticados há mais de cinco (5) anos, salvo quando houver afronta direta à Constituição.

Art. $123 \mathrm{O}$ controle dos atos administrativos praticados por membros, órgãos e serviços auxiliares do Ministério Público será exercido pelo Conselho, de ofício ou mediante provocação, sempre que restarem contrariados, em tese, os princípios estabelecidos no artigo 37 da Constituição Federal. (Regimento Interno do CNMP) 
Parágrafo único. Não será admitido o controle de atos administrativos praticados há mais de cinco anos, salvo quando houver afronta direta à Constituição Federal.

O controle dos atos administrativos pressupõe: a) a existência do ato com presunção de legalidade típica, não se admitindo, por interpretação lógica, a atuação no sentido de repressão a ato que está em vistas a aperfeiçoar-se, salvo se for derivado de ato já existente (v.g.: uma convocação para determinado ato em concurso público - o ato a ser impugnado é o próprio Edital ou decisão em fase anterior à convocação) e b) a legitimidade de atuação que consiste na possibilidade do Conselho em atuar frente ao ato administrativo que nada mais é que a verificação se está no prazo decadencial quinquenal, salvo se tratar de afronta direta à Constituição Federal.

Frise-se que o ato deve ser exclusivamente de caráter administrativo. Isso por que embora a matéria possa tratar de tema afeito à competência dos Conselhos não se admite a impugnação de ato judicial perante o CNJ ou CNMP dada sua função orgânica administrativa e não judicial.

Importante contribuição é a que se extrai da decisão do Min. CELSO DE MELLO nos autos do MS 28598 MC que fixou entendimento de que, in casu, embora se trate de matéria referente à organização cartorária, expressamente inclusa na competência do $\mathrm{CNJ}$, o órgão estaria vedado a se pronunciar tendo em vista que, após a judicialização da matéria em primeiro grau, sobreviera sentença de mérito que decidiu a causa. Ora, o CNJ estaria a desconstituir sentença judicial não transitada em julgado, fazendo as vezes de Tribunal em evidente afronta ao sistema judicial.

De sorte, no mesmo sentido é o Min. EROS GRAU nos autos da ADI 3.367/DF, que magistralmente escreve:

De resto - e este ponto é de fundamental importância - ao Conselho Nacional de Justiça não é atribuída competência nenhuma que permita a sua interferência na independência funcional do magistrado. Cabe a ele, exclusivamente, o 'controle da atuação administrativa e financeira do Poder Judiciário e do cumprimento dos deveres funcionais dos juízes', nada mais do que isso. Sua presença, como órgão do Poder Judiciário, no modelo brasileiro de harmonia e 
equilíbrio entre os poderes, não conformará nem informará - nem mesmo afetará - o dever-poder de decidir conforme a Constituição e as leis que vincula os membros da magistratura. O controle que exercerá está adstrito ao plano 'da atuação administrativa e financeira do Poder Judiciário e do cumprimento dos deveres funcionais dos juízes'. Embora órgão integrante do Poder Judiciário - razão pela qual desempenha autêntico controle interno - não exerce função jurisdicional. ${ }^{5}$

Conclui-se, portanto, que a atuação administrativa no sentido de repelir atos administrativos que estejam em dissonância do texto constitucional é prerrogativa dos Conselhos Nacionais de forma absolutamente restrita dada a hierarquia desses em relação aos demais entes do Poder Judiciário e dos órgãos do Ministério Público, não sendo verdade que tal hierarquia se processe fora do âmbito administrativo intervindo o Conselho em desconstituição de decisão judicial.

Embora tais considerações sejam convergentes para a maioria dos estudiosos há que se indagar sob o teor da Súmula 473/STF, que mais à frente será objeto de minucioso comentário, se os atos administrativos impugnados judicialmente não podem ser objeto de controle pelos Conselhos Nacionais.

Não parece lógica tal vedação posto que a anulação de determinado ato, exempli gratia, faria com que na esfera judicial houvesse extinção do feito sem resolução do mérito por perda superveniente do objeto da demanda, como é possível acontecer em ações diversas nas quais não há mais resistência ao pedido pelo reconhecimento pelo polo passivo da pretensão ativa.

Não é defensável, entretanto, que a atuação material do Conselho Nacional seja no sentido de desprestigiar a supremacia da análise judicial das questões, isto é, quando decididos com mérito, as questões levadas ao Judiciário, não há defesa suficiente, sob pena de violação constitucional garantida pela inafastabilidade da jurisdição.

\footnotetext{
5 ADI 3367, Relator(a): Min. CEZAR PELUSO, Tribunal Pleno, julgado em 13/04/2005, DJ 17-03-2006 PP-00004 EMENT VOL-02225-01 PP-00182 REPUBLICAÇÃO: DJ 2209-2006 PP-00029
} 


\section{CONTROLE DE CONSTITUCIONALIDADE DOS ATOS ADMINISTRATIVOS}

O controle de constitucionalidade funda-se no princípio da supremacia da Constituição Federal. Segundo José Afonso da Silva, é o princípio pelo qual a Constituição está no vértice do sistema jurídico do país e é a norma que confere validade e legitimidade a todos os poderes estatais que reconheça e na proporção por ela distribuídos ${ }^{6}$.

Daí advém que, quando determinada norma estiver em conflito com a lei que ocupa o vértice do sistema jurídico, ela é concebida como inconstitucional contrária ao ordenamento pátrio e, portanto, passível de ser rechaçada do arcabouço jurídico como forma de legitimar os princípios estabelecidos pela Lex fundamental.

Assim, diversos são os ataques possíveis a atos administrativos frente à sua não consonância com a Constituição Federal. A depender da autoridade cuja Constituição reserva prerrogativas para edição de determinado ato, o sujeito incompetente violaria o pressuposto subjetivo do ato administrativo. Se o conflito recai sobre o pressuposto fático do ato, há violação dos motivos que constituíram o ato, assim, o ensinamento de Celso Antônio Bandeira de Mello: "o ato será viciado toda vez que o motivo de fato for descoincidente com o motivo legal" 7

Entretanto, qualquer que seja o fundamento, sempre haverá violação ao texto constitucional já que sendo o Poder Judiciário um dos basilares Poderes Republicanos, sua organicidade encontra-se definida no texto maior, resultando seus atos administrativos do exercício regular desse Poder pulverizado na organização administrativo-jurisdicional.

O ato administrativo, portanto, é passível de repreensão administrativa ainda que para tanto se utilize do fundamento constitucional como razão decisória em vista à cogente observância do texto constitucional.

O controle de constitucionalidade, por sua vez, é exercido pela via judicial de forma difusa ou concentrada. Na forma concentrada, a declaração de inconstitucionalidade compete precipuamente ao Supremo Tribunal Federal a quem cabe a guarda da Constituição (Art. 102, CF), produz efeitos erga omnes, ou seja, de caráter vinculante a todos os poderes da

\footnotetext{
${ }^{6}$ SILVA, José Afonso da. Curso de Direito Constitucional Positivo. 25. ed. São Paulo: Malheiros, 2005. p.45.

${ }^{7}$ MELLO, Celso Antonio Bandeira. Curso de Direito Administrativo. 26. ed. São Paulo: Malheiros, 2008. p. 391e ss.
} 
República e observância obrigatória, além de ter requisitos especiais para o rito de sua declaração inclusive com rol numerus clausus dos legitimados à arguição de inconstitucionalidade.

Já o controle difuso de constitucionalidade é exercido pelo Poder Judiciário em seu todo e é praticado, por via de exceção na qual cabe à parte interessada arguir no processo, a eventual inconstitucionalidade, produzindo efeitos inter partes.

Apesar da competência unicamente jurisdicional para o controle de constitucionalidade que se obtém por uma análise perfunctória do texto, a própria Constituição Federal, a nosso ver, consagrou o poder-dever de zelo e guarda a seu texto impondo aos administradores que se fizessem observar e se norteassem pelo que ela própria prescreve. Tal afirmação está consubstanciada no Artigo 23, inciso I da Constituição Federal, in verbis:

Art. 23 - É competência comum da União, dos Estados, do Distrito Federal e dos Municípios:

I - zelar pela guarda da Constituição, das leis e das instituições democráticas e conservar o patrimônio público;

Tal prescrição não é texto vago ao qual se podem cerrar os olhos. O zelo pela guarda da Constituição materializa-se no seu devido cumprimento e respeito, em que pesem os ditados princípios administrativos a que também o Poder Judiciário está adstrito por integrar, como um todo para fins administrativos: a Administração Pública.

Considerações ainda pertinentes ao nosso trabalho são as decorrentes do poder discricionário da Administração. Segundo Celso Antonio Bandeira de Mello, ato administrativo efetuado na utilização do poder discricionário é aquele que a Administração pratica com certa liberdade e poder de decisão da melhor forma de se praticar o ato ${ }^{8}$. Não dispensa o ato discricionário, entretanto, obediência à lei que rege e permite a edição do ato, além da já comentada e necessária vinculação à Constituição da República.

Em suma, Celso Antonio Bandeira de Mello preceitua, arrematando a matéria:

\footnotetext{
${ }^{8}$ MELLO, Celso Antonio Bandeira. Curso de Direito Administrativo. 26. ed. São Paulo: Malheiros, 2008. p. 424.
} 
[Discricionariedade é] a margem de liberdade conferida pela lei ao administrador a fim de que este cumpra o dever de integrar com a sua vontade ou juízo a norma jurídica, diante do caso concreto, segundo critérios subjetivos próprios, a fim de dar satisfação aos objetivos consagrados no sistema legal. ${ }^{9}$

Logo, ainda que o ato seja discricionário, está adstrito à lei e também à hierarquia administrativa interposta à autoridade que emanou o ato, interposição essa decorrente do princípio hierárquico administrativo. Assim, não se cogita, por conseguinte, a impossibilidade de reapreciação dos motivos discricionários pelos quais optou o administrador hierarquicamente inferior sob pena de solubilidade de todo um sistema constituído, reapreciação esta, administrativamente possível aos Conselhos Nacionais.

Os Conselhos Nacionais, não obstante a observância da Constituição Federal quanto ao sistema de controle de constitucionalidade, têm se pronunciado por diversas vezes pela não aplicabilidade de leis ou atos normativos considerados, por sua decisão, como inconstitucionais. Isso por que se fundam no permissivo legal de que a todos os Poderes estatais competem o zelo e guarda pela Constituição Federal (Art. 23, I da CF) de forma, inclusive, a legitimar a negativa de eficácia de determinadas leis.

Nesse sentido, é a lição de Reale:

todos os Poderes têm a missão de guarda da Constituição, e não o Judiciário, e a todos é de rigor cumpri-la, toda vez que tenham que agir no âmbito de sua esfera de atribuições ${ }^{10}$

Sobre o tema, Abreu assevera negativamente a essa postura em comentário crítico à decisão do Conselho Nacional de Justiça nos autos do Procedimento de Controle Administrativo no 395:

\footnotetext{
${ }^{9}$ MELLO, Celso Antonio Bandeira. Curso de Direito Administrativo. 26. ed. São Paulo: Malheiros, 2008. p. 426.

${ }^{10}$ REALE, Miguel. Parecer. Diário Oficial do Estado de São Paulo. 19 mar 1963 Apud POLETTI, Ronaldo Rebello de Britto. Controle da Constitucionalidade das Leis. 2. ed. Rio de Janeiro: Forense, 2001, p. 137.
} 
A questão é que, quando dispositivos legais estaduais são impugnados face à Constituição, artigo 236, como no presente caso, e apreciados originariamente numa só "corte", estamos diante de um típico procedimento de controle concentrado de normas, instrumentalizado por meio da Ação Direta de Inconstitucionalidade. ${ }^{11}$

Entretanto, nosso posicionamento é diverso e vai de encontro com o exarado pelo ex-conselheiro do CNJ Douglas Alencar em resposta à crítica sobre sua decisão no PCA no 395.

Até mesmo a possibilidade de o Administrador Público deixar de aplicar normas jurídicas que considere inconstitucionais é inequívoca e reconhecida inclusive pela Excelsa Corte. Nesse exato sentido já decidiu reiteradas vezes o CNJ, entendendo que o Administrador Público está autorizado pelo sistema constitucional vigente, embora assumindo os ônus de sua conduta, a negar aplicação a preceito legal que considere contrário ao Texto Constitucional. Afinal, se a Constituição ocupa o ápice do ordenamento jurídico, vinculando direta e objetivamente a todos os cidadãos, especialmente os Administradores Públicos (CF, artigo 37), recusar aplicação a preceito legal reputado inconstitucional constitui, mais do que mera faculdade, autêntica obrigação jurídica. ${ }^{12}$

De fato, a mera utilização de fundamento constitucional utilizada como razões do decisum não invade a competência do Pretório Excelso posto que a inobservância das normas constitucionais seria negar vigência à Lex Mater. Assim, constitui-se o paradigma se ao administrador é conferida a possibilidade de afastar a aplicação da norma inconstitucional, na

\footnotetext{
${ }^{11}$ ABREU, Fabiano Rodrigues de. CNJ atropela Supremo e faz controle de constitucionalidade. ConJur - Consultor Jurídico. Disponível em < www.conjur.com.br/2007-mai18/cnj_atropela_stf_faz_controle_constitucionalidade?imprimir=1>. Acesso em dez 2013. ${ }^{12}$ RODRIGUES, Douglas Alencar. CNJ não faz controle de constitucionalidade. ConJurConsultor Jurídico. Disponível em < www.conjur.com.br/2007-mai-23/cnj_nao_faz_controle_constitucionalidade?imprimir=1 >. Acesso em dez 2013.
} 
qual se funda o ato administrativo, ou se tal prática estaria a ferir o princípio da separação dos poderes que garante que o exercício das prerrogativas de determinado poder inibe o exercício de outro.

Para Willeman a oposição fica assim definida:

O dilema pode ser sintetizado nos seguintes termos: como deve o Estado-Administração proceder diante de uma lei que repute inconstitucional? Deve privilegiar a vinculação administrativa à Constituição e ignorar $o$ princípio da presunção de constitucionalidade das leis e a primazia do controle repressivo jurisdicional? Ou, inversamente, deve aplicar a lei, não obstante reputá-la inconstitucional, e provocar a judicial review? ${ }^{13}$

Há que se considerar que o sistema brasileiro de controle de constitucionalidade, destarte da doutrina majoritária, não deixou como exclusiva a apreciação de constitucionalidade dos atos normativos pelo Poder Judiciário. Isso por que, embora a palavra final seja do Judiciário haja vista que só esse pode proclamar a coisa julgada, não há impedimento legal para a apreciação, à luz da Constituição Federal, para que os órgãos administrativos na sua missão de zelar e guardar a Carta da República, no sentido de negar eficácia ao ato normativo, sendo esse o único meio possível e eficiente para resguardar os fundamentos constitucionais invocados.

Sob esse aspecto, a doutrina de Themístocles Brandão Cavalcanti e Carlos Maximiliano ${ }^{14}$ convergentes em afirmar a possibilidade de não aplicação, no âmbito administrativo, de atos normativos (que por sua vez influenciam os atos administrativos), que estejam em manifesta dissonância da Constituição.

No magistério de Brandão temos que embora haja a presunção de constitucionalidade das leis e atos dela decorrentes, isso não significa que

${ }^{13}$ WILLEMAN, Marianna Montebello. Controle de constitucionalidade por órgãos não jurisdicionais: a interpretação constitucional fora das cortes de justiça. Revista da Procuradoria Geral do Estado do Espírito Santo, v. 12, n. 12, 1\%2º sem. 2012. p. 291.

${ }^{14}$ MAXIMILIANO, Carlos. Comentários à Constituição brasileira de 1891. Brasília: Senado Federal, Conselho Editorial, 2005. 
sejam elas intangíveis o que, porém, exige do hermeneuta um exacerbado rigor em sua fundamentação ${ }^{15}$.

De sorte, temos que, na prática, os atos normativo e administrativo sempre estarão sujeitos à apreciação judicial em face do princípio da inafastabilidade da jurisdição calcado no rol de direitos e garantias fundamentais (Art. $5^{\circ}, \mathrm{XXXV}$ ), o que muda é sob qual ótica se dará tal apreciação: se da ótica e interesses jurídicos do prejudicado pelo ato administrativo, calcado esse no ato normativo autorizante ou fundante que se reputa inconstitucional, ou pela ótica e interesses jurídicos da autoridade e instituição da qual emanou tal ato administrativo, que, por óbvio, será a defesa do ato que editou.

Teria a Administração, e nela incluso o Poder Judiciário, guarida constitucional em aplicar norma que verifica ser absolutamente contrária à Lei Principal, para embasar seus atos? Parece-nos que tal premissa faz com que a alegada exclusividade de apreciação de constitucionalidade de atos pelo Poder Judiciário em sua função judicante contradiz a própria Constituição, pois seria admitir que frente a essa exclusividade determinado ato flagrantemente inconstitucional tivesse vida e produzisse efeitos jurídicos até intervenção jurisdicional, sobrevivendo no mundo jurídico que previamente o renegou pelos ditames e concretude teleológica da Lex Mater. Parece-nos que o caminho mais adequado, em resposta à antagonização proposta por Willeman, seria a judicial review dos atos administrativos que negaram aplicação de lei tida como inconstitucional, ainda que não houvesse sua declaração com efeitos erga omnes.

O entendimento de que a Administração deve aplicar lei inconstitucional porque é tida como constitucional no seu aspecto formal, em observância ao estrito processo legislativo constitucional, não pode ser tido como válido, haja vista o teor da Súmula 473/STF pela qual a Administração pode "anular seus próprios atos, quando eivados de vícios que os tornam ilegais, porque deles não se originam direitos". Ainda nos casos em que a inconstitucionalidade é no duplo aspecto (formal e material), o dever de inaplicação de lei inconstitucional é mais latente porque objetivamente mais aferível em razão da inobservância dos preceitos objetivos que guiam a produção das leis.

${ }^{15}$ CÉSAR, Marcelo Vieira de Sousa. Controle de Constitucionalidade pela Administração Tributária. Revista da Procuradoria Geral da Fazenda Nacional. Ano II, Vol. 4, 2012. p. 105. 
A ilegalidade a que se refere a Súmula 473/STF deve ser interpretada de forma latíssima, uma vez que seria evidente afronta ao princípio da eficiência da Administração Pública exarar ato de flagrante inconstitucionalidade, gerando efeitos imediatos perante a Administração e seus administrados do que postergar tais efeitos que podem ser declarados posteriormente mediante revisão judicial do ato administrativo. Isto por que, o que se perseguiria em eventual processo de arguição de inconstitucionalidade em sede cautelar é justamente a suspensão dos efeitos da lei atacada. E mais, salvo modulação temporal da declaração, todos os atos originados pela lei inconstitucional serão também fulminados, dada a perda de seu fundamento.

Sousa César refere-se a essa possibilidade advinda da Súmula 473/STF como o exercício regular do direito de autotutela da Administração Pública. E complementa:

Trata-se de aplicação do princípio da autotutela, como também da economicidade, pois determina que, verificado um ato que ofenda a legislação infraconstitucional ou a própria Constituição Federal, não poderá o poder público insistir no erro e convalidar o ato viciado ou postergar para o Judiciário o encargo de invalidá-lo, sob pena de causar prejuízos desnecessários aos cofres públicos. Deve a Administração invalidar, portanto, os atos administrativos inquinados de inconstitucionalidade, ainda que conformes à letra da lei considerada inconstitucional. ${ }^{16}$

Até mesmo aqueles que defendem para os atos administrativos sob o aspecto que aqui se analisa, que esses gozam de presunção de legalidade, não pode o princípio da legalidade ser invocado para que a lei inconstitucional permita edição de atos que, por arrastão serão também inconstitucionais. Isto por que tal princípio, de longe, e nem poderia, desprezar a Constituição da República que está no cume, reforçando novamente a supremacia constitucional. Seria ilógico defender que lei inconstitucional

\footnotetext{
${ }^{16}$ CÉSAR, Marcelo Vieira de Sousa. Controle de Constitucionalidade pela Administração Tributária. Revista da Procuradoria Geral da Fazenda Nacional. Ano II, Vol. 4, 2012. Disponível em < http://www.pgfn.fazenda.gov.br/revista-pgfn/ano-ii-numero-iv/ano-ii-numero-4-2012 >. Acesso em dez 2013.
} 
fosse aplicada, com base na legalidade, haja vista a nulidade que se apresenta $^{17}$. Seria basear-se pelo nulo, que não tem efeito algum, para defender a legalidade.

Nesse sentido, enumerando argumentos favoráveis da vinculação do administrador público aos preceitos constitucionais, Juarez Freitas diz que a atuação do administrador é legítima porque, dentre outros aspectos, cria um clima cultural favorável à dimensão civilizatória da Constituição, diminui a litigiosidade contra o Estado-Administração, respeito ao princípio da deferência, com o acolhimento na prática da presunção de legitimidade constitucional dos atos administrativos e outros ${ }^{18}$.

\section{CONCLUSÃO}

Em vista de todo o exposto, verifica-se que a Constituição Federal permite aos órgãos administrativos de controle externo da Administração Pública o controle de constitucionalidade dos seus atos administrativos, a uma, por força do comando incluso no Artigo 23, I que incumbe a todos os entes federativos a guarda e zelo da Constituição; a duas, por força da Súmula 473/STF que permite a anulação de atos administrativos pela própria Administração quando eivados de vícios ou ilegalidades, incluída nesta semântica a inconstitucionalidade decorrente do princípio da autotutela e economicidade e a três, porque há evidente respeito à supremacia da Constituição quando o fundamento da invalidade do ato administrativo impede de seu próprio texto ou princípios.

\section{REFERÊNCIAS BIBLIOGRÁFICAS}

ABREU, Fabiano Rodrigues de. CNJ atropela Supremo e faz controle de constitucionalidade. ConJur - Consultor Jurídico. Disponível em < www.conjur.com.br/2007-mai18/cnj_atropela_stf_faz_controle_constitucionalidade?imprimir=1 $>$.

\footnotetext{
${ }^{17}$ Ibidem .

${ }^{18}$ Ibidem.
} 
BAGATINI, Júlia. Conselho Nacional de Justiça: um controle administrativo do poder judiciário?. In: Âmbito Jurídico, Rio Grande, XIV, n. 88, maio 2011. Disponível em: < http://www.ambito-

juridico.com.br/site/index.php?n_link=revista_artigos_leitura\&arti go_id $=9498>$.

BANCO MUNDIAL. O setor judiciário na América Latina e no caribe: elementos para reforma. Documento Técnico $\mathbf{n}^{0} 319$. Disponível em < http://www.anamatra.org.br/uploads/document/00003439.pdf $>$.

CÉSAR, Marcelo Vieira de Sousa. Controle de Constitucionalidade pela Administração Tributária. Revista da Procuradoria Geral da Fazenda Nacional. Ano II, Vol. 4, 2012. Disponível em < http://www.pgfn.fazenda.gov.br/revista-pgfn/ano-ii-numero-iv/anoii-numero-4-2012 >.

MAXIMILIANO, Carlos. Comentários à Constituição brasileira de 1891. Brasília: Senado Federal, Conselho Editorial, 2005.

MELLO, Celso Antonio Bandeira. Curso de Direito Administrativo. 26. ed. São Paulo: Malheiros, 2008.

POLETTI, Ronaldo Rebello de Britto. Controle da Constitucionalidade das Leis. 2. ed. Rio de Janeiro: Forense, 2001.

RODRIGUES, Douglas Alencar. CNJ não faz controle de constitucionalidade. ConJur - Consultor Jurídico. Disponível em < www.conjur.com.br/2007-mai-

23/cnj_nao_faz_controle_constitucionalidade?imprimir $=1$ >.

SILVA, José Afonso da. Curso de Direito Constitucional Positivo. 25. ed. São Paulo: Malheiros, 2005.

WILLEMAN, Marianna Montebello. Controle de constitucionalidade por órgãos não jurisdicionais: a interpretação constitucional fora das cortes de justiça. Revista da Procuradoria Geral do Estado do Espírito Santo, v. 12, n. 12, 1\%2\% sem. 2012. 
